\title{
Individual savings accounts for social insurance: rationale and alternative designs
}

\author{
A. Lans Bovenberg • Martin Ino Hansen • \\ Peter Birch Sørensen
}

Published online: 8 August 2007

(C) Springer Science+Business Media, LLC 2007

\begin{abstract}
Using Danish data, we find that about three-fourths of the taxes levied to finance public transfers actually finance benefits that redistribute income over the life cycle of individual taxpayers rather than redistribute resources across people. This finding and similar results for other countries provide a rationale for financing part of social insurance via mandatory individual savings accounts. We discuss the advantages and disadvantages of mandatory individual savings accounts for social insurance and survey some recent alternative proposals for such accounts.
\end{abstract}

Keywords Social insurance $\cdot$ Individual accounts $\cdot$ Lifetime income distribution

\section{JEL Classification $\mathrm{H} 53 \cdot \mathrm{H} 55$}

\section{Introduction}

Redistribution from rich to poor and social insurance against income losses are basic functions of the welfare state. Yet public policy discussions rarely acknowledge that in modern welfare states, a large part of the taxes levied to finance social transfers merely redistributes resources from one stage in the taxpayer's life cycle to another.

\footnotetext{
A.L. Bovenberg $(\bowtie)$

CentER and Netspar, Tilburg University, P.O. Box 90153, 5000 LE Tilburg, The Netherlands e-mail: A.L.Bovenberg@uvt.nl
}

\section{M.I. Hansen}

Statistics Denmark, Sejrøgade 11, 2100 Copenhagen, Denmark

e-mail:mih@dst.dk

P.B. Sørensen

Department of Economics, University of Copenhagen, Studiestraede 6, 1455 Copenhagen K, Denmark

e-mail: Peter.Birch.Sorensen@econ.ku.dk 
In other words, a considerable part of the tax bill does not redistribute resources from the lifetime rich to the lifetime poor but is essentially income that the taxpayer transfers to himself over his own life course. However, since there is rarely an actuarial link between (social security) taxes paid and social transfers received, taxes and transfers inevitably distort labor supply. Moreover, transfer programs often create moral hazard, as taxpayers have no incentive to reduce their reliance on transfers.

In this paper, we argue that mandatory individual savings accounts can play a useful role in financing social benefits that exert only little redistributive power from a life-cycle perspective and that give rise to serious moral hazard. For such benefits, savings accounts can enhance labor-market incentives at a relatively low cost in terms of a more unequal distribution of lifetime incomes. Indeed, when individual accounts are combined with a borrowing facility to alleviate liquidity constraints, and when they are also complemented by a minimum public pension that guarantees a minimum lifetime income for everyone, such an account system has the potential to enhance incentives without substantially increasing inequality in lifetime incomes.

The main purpose of the paper is to provide a non-technical discussion of the case for individual accounts ('welfare accounts') and to review alternative proposals for the design of an account system. To limit the scope of the paper, we focus on the financing of social transfers to people of working age and do not consider proposals for reform of the system of old-age social security (although we do explain how the individual accounts for the working population could be integrated with the pension system).

To motivate the relevance of individual accounts, we start in Sect. 2 by documenting the rather low degree to which current social-insurance programs redistribute lifetime incomes. Using Danish data, we find that about three-fourths of the taxes levied to fund public transfers merely finance benefits that redistribute income over the same taxpayer's life cycle rather than between different people. Section 3 then discusses the theoretical rationale for social insurance based on individual savings accounts, while Sect. 4 reviews alternative proposals for the design of welfare accounts for the working population. Section 5 summarizes our main conclusions.

\section{Empirical motivation: intrapersonal versus interpersonal redistribution in the modern welfare state}

In recent years, several empirical studies have investigated the extent to which social insurance benefits redistribute resources over the taxpayer's own life cycle rather than redistributing lifetime income from rich to poor. This section presents a new case study of redistribution in the Danish welfare state and offers a brief overview of similar studies for other countries.

The starting point for most of the studies is an estimate of the distribution of lifetime incomes. This is typically based on a micro panel data set covering a representative cross section of the population over some time period. Armed with such data, one can link the annual incomes of individuals in different age groups (but with otherwise similar characteristics) to obtain a series of annual incomes covering an entire life cycle. To illustrate, suppose the data set covers a five-year period, and that individual 
$X$ belonged to the age interval $46-50$ years during that period, while individual $Y$ with similar socioeconomic characteristics lived through the age interval 50-54 years in the data period. Furthermore, suppose that, in addition to belonging to the same socioeconomic group, $X$ and $Y$ had roughly the same annual real income at the age of 50. By matching these two individuals, including them in a single constructed life cycle, one can obtain a series of annual incomes in the age interval 46-54 years in the life cycle of a person with certain characteristics. By proceeding to match $X$ and $Y$ with similar individuals belonging to younger and older age intervals during the data period, one ends up with a series of annual incomes covering a full life cycle.

Once one has constructed measures of pre-tax and disposable lifetime incomes for a representative sample of the population, one can compare the tax bill paid over an individual's life cycle to the social transfers received by that same taxpayer over the life cycle. Most studies estimate the fraction of the aggregate direct and indirect tax bill that serves to finance social insurance transfers. They then assume that a similar fraction of each individual's tax bill finances social transfers. By relating this fraction of the lifetime tax bill to the total transfers received over the life cycle, one obtains a measure of the degree to which the taxes paid over an individual's life are transferred back to that same person-either in the same year or in some other year in the life cycle. This type of redistribution over the life cycle is usually referred to as intrapersonal redistribution, whereas taxes that redistribute lifetime income across individuals is termed interpersonal redistribution.

In Table 1 below, we present an estimate of the amount of interpersonal versus intrapersonal redistribution in the Danish welfare state, using the most recent estimates of lifetime incomes in Denmark, presented in the spring 2005 report of the Danish Economic Council (2005). These calculations account for all monetary public transfers paid to Danish households, but they do not include the value of public services delivered to households. ${ }^{1}$ Box 1 explains how we have separated interpersonal from intrapersonal redistribution, adopting a methodology previously used by Hussénius and Selén (1994), Falkingham and Harding (1996), O’Donoghue (2001), and Pettersson and Pettersson (2003). Specifically, Box 1 explains how the numbers in rows 2 through 6 in Table 1 were calculated.

\section{Box 1 (Measuring interpersonal and intrapersonal redistribution in Denmark)}

The first step in the estimation of the interpersonal and intrapersonal redistribution achieved through the tax-transfer system is to identify the fraction of taxes serving to finance social-insurance transfers. The total social-insurance benefits received over the life cycles of the representative $10 \%$ sample of Danish households included in our data set amount to $43.7 \%$ of the total direct and indirect taxes paid by these same individuals over their lifetimes, with the remaining fraction of taxes financing other categories of public spending. In our main scenario, we therefore assume that $43.7 \%$ of direct and indirect taxes are 'reserved' for the financing of social-insurance benefits. The direct taxes paid by each individual in

\footnotetext{
${ }^{1}$ Hansen (2005) explains in detail how the estimates of lifetime incomes for Denmark were produced.
} 


\section{Box 1 (Continued)}

each year of his life cycle are explicitly included in our data set, so we take $43.7 \%$ of these payments to represent the financing of social insurance. Individual payments of indirect taxes are not explicitly included in our data, however, so these payments have to be estimated. According to the Danish Ministry of Finance (2002), the indirect taxes paid by the average Danish taxpayer amount to $22.3 \%$ of disposable income, varying from $37.4 \%$ of annual disposable income in the bottom income decile to $16.4 \%$ of annual disposable income in the top decile. We use these estimates to impute indirect tax payments to all individuals in our sample, accounting for the income decile to which they belong in each year of their life cycle. The fraction of income devoted to indirect taxes thus varies as individuals move from one place in the annual income distribution to another over the life cycle. Having allocated indirect taxes across individuals in this way, we assume that $43.7 \%$ of these payments are 'reserved' for the financing of social-insurance benefit.

The next step is to separate the interpersonal redistribution achieved via the social-insurance system (i.e. redistribution of lifetime incomes from rich to poor) from the intrapersonal redistribution (i.e. redistribution over the individual's life cycle). We therefore define the net lifetime transfer received by individual $i$ over the life cycle as

$$
N_{i}=\sum_{t}\left(B_{i t}-T_{i t}\right)
$$

where $B_{i t}$ denotes transfers received by individual $i$ in year $t$, and $T_{i t}$ is the part of individual $i$ 's direct and indirect tax payment in year $t$ that is 'reserved' for the financing of social insurance. The total interpersonal redistribution achieved in a life-cycle perspective (INTER) is found by aggregating the net lifetime transfers across those individuals for whom the net transfer received is positive:

$$
\text { INTER }=\sum_{i}\left(N_{i} \mid N_{i}>0\right)=-\sum_{i}\left(N_{i} \mid N_{i}<0\right) .
$$

The intrapersonal redistribution can be split into two components. Within any year in which an individual receives a transfer, he will also pay some amount of tax (at least indirect tax), so that part of the transfer received is self-financed. We define the part of the transfer financed by the taxpayer himself within the same year as

$$
S Y_{i t}=\min \left(B_{i t}, T_{i t}\right) .
$$

Another part of the transfers received over the life cycle is financed by the recipient himself via the taxes paid in the other years of his life. This self-financing of benefits via the 'reserved' taxes paid in some other year may be calculated as

$$
\begin{array}{ll}
O Y_{i}=\sum_{t}\left(T_{i t}-S Y_{i t}\right) & \text { if } N_{i}>0, \\
O Y_{i}=\sum_{t}\left(B_{i t}-S Y_{i t}\right) & \text { if } N_{i} \leq 0 .
\end{array}
$$




\section{Box 1 (Continued)}

The total intrapersonal redistribution (INTRA) is the sum of the self-financing by all individuals within the same year and across their life cycles:

$$
I N T R A=\sum_{i} \sum_{t} S Y_{i t}+\sum_{i} O Y_{i} .
$$

We have now decomposed total transfer payments into interpersonal and intrapersonal redistribution, since the definitions given above imply that

$$
I N T E R+I N T R A=\sum_{i} \sum_{t} T_{i t}=\sum_{i} \sum_{t} B_{i t} .
$$

All numbers in Table 1 are average payments accumulated over the life cycle, accounting for observed differences in life expectancies across income deciles. To put the numbers in the subsequent rows in perspective, the first row shows the average lifetime factor income (income before taxes and transfers) in the various deciles. The second row from the bottom of Table 1 shows the average net transfer received by those who end up with positive net receipts from the government over their life cycles (those for whom $N_{i}>0$ ). In the bottom row, we report the average net taxes paid by those who end up paying more to the government than they receive $\left(N_{i} \leq 0\right)$. Not surprisingly, most of the net recipients are concentrated in the lower lifetime income groups, while most of the net tax payments are concentrated in the top income groups. This reveals that some amount of redistribution from rich to poor does after all take place.

The first ten columns in Table 1 contain average accumulated lifetime payments/receipts for each of the ten income deciles. The final column reports averages across the entire population. Adding the figures in the fourth and fifth rows in the final column and dividing the sum by the figure in the second row of that same column, we find that $74 \%$ of the taxes levied to finance social insurance represent intrapersonal redistribution over the taxpayer's own life cycle, leaving only $26 \%$ of tax revenues for interpersonal redistribution from high- to low lifetime incomes. Moreover, it is striking that even at the bottom of the income distribution some people are net taxpayers on a lifetime basis, while at the top of the distribution some people receive net benefits over their life course.

The studies by Hussénius and Selén (1994), Falkingham and Harding (1996), O'Donoghue (2001), and Pettersson and Pettersson (2003) all use variants of the method outlined above. Hussénius and Selén (1994) estimated that for the average taxpayer in the early 1990 s only about $24 \%$ of the taxes levied to finance social insurance in Sweden accomplished interpersonal redistribution. Pettersson and Pettersson (2003) recently updated and refined the estimates by Hussénius and Selén, estimating lifetime incomes with the aid of a dynamic micro-simulation model and including the value of important public services such as education, health care and care for the elderly in a comprehensive measure of lifetime income. With this extended concept 


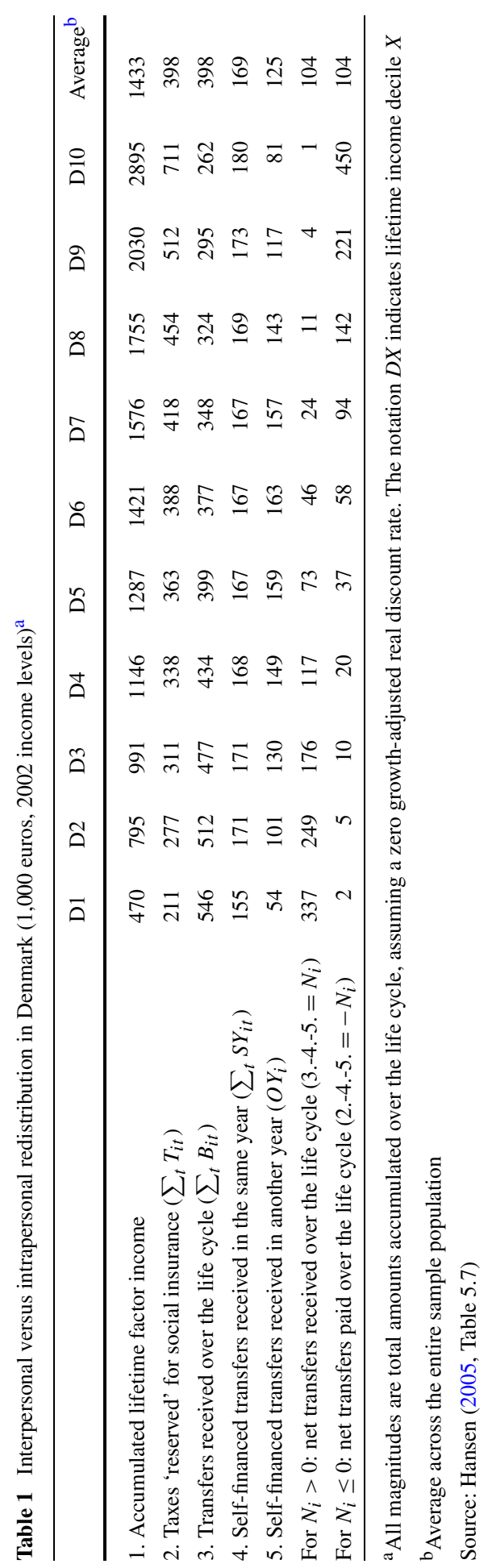


of income, Pettersson and Pettersson found that only $18 \%$ of the taxes levied to finance social insurance transfers and social services in Sweden can be categorized as interpersonal redistribution. Falkingham and Harding (1996) found a degree of interpersonal redistribution between 48 and $62 \%$ in Australia and between 29 and $38 \%$ in Great Britain, depending on the extent to which indirect taxes are assumed to contribute to the financing of social transfers. For Ireland and Italy, O'Donoghue (2001) estimated a degree of interpersonal redistribution of 45 and $24 \%$, respectively. The strong message from all of these studies is that a large part of the taxes levied to finance social insurance transfers in the modern welfare state merely achieves a redistribution of resources from one stage in the taxpayer's life cycle to another rather than a redistribution from the lifetime rich to the lifetime poor.

Several other studies have explored lifetime distribution and how it is affected by public policy. Nelissen (1998) employs a micro-simulation model to investigate how social insurance affects income distribution on a lifetime basis in the Netherlands. Similar studies for the United States include Coronado et al. (2000), Gustman and Steinmeier (2000), and Liebman (2001). These studies find that social insurance does help to redistribute from the lifetime rich to the lifetime poor. The contribution of social insurance to the redistribution of lifetime incomes, however, is considerably smaller than what is suggested by its contribution to the redistribution of annual incomes. To illustrate, Nelissen (1998) finds that the Dutch social insurance system reduces annual income inequality by $45 \%$ but lifetime inequality only by between 15 and $30 \%$ (depending on the discount rate and on the historical cohort considered). ${ }^{2}$

\section{The theoretical rationale for social insurance based on individual savings accounts}

As an alternative or supplement to tax-financed transfers, the consumption-smoothing function of the welfare state can be accomplished also through savings schemes that link taxes and benefits on an individual level. In such a scheme, workers contribute part of their earnings to an individual savings account that is debited when the owner draws social-insurance benefits. At the time of retirement, any surplus on the account is used to supplement retirement benefits. By linking benefits to contributions in an actuarially fair way, the savings accounts reduce the tax wedge on labor income. Social security contributions essentially become benefit taxes. ${ }^{3}$ Moreover, moral hazard in taking up benefits is discouraged, as the benefits are paid out of the accounts rather than the common insurance pool. In this way, the accounts reap a double dividend: a broader tax base on account of better labor-supply incentives produced by more actuarially fair contributions and less benefit take-up due to less moral hazard.

\footnotetext{
${ }^{2}$ Ter Rele (2005) covers a broader range of Dutch governmental programs, but does not account for all heterogeneity and restricts himself to an analysis of the life cycles of six educational groups. He finds that public programs substantially reduce inequality on a lifetime basis. Whereas lifetime tax liabilities are proportional to lifetime incomes, lifetime benefits of public spending do not vary with lifetime income.

${ }^{3}$ To the extent that existing social-security contributions finance wage-linked benefits, they are in fact already, at least in part, benefit taxes.
} 
With well-functioning capital markets, rational forward-looking behavior and no redistributional concerns, the government can rely on voluntary saving to accomplish consumption smoothing over the life course. Compulsory savings accounts can help address imperfect capital markets giving rise to liquidity constraints, just as they may help to address policy concerns regarding lifetime redistribution, lack of self control, and moral hazard in insurance. We explore these possible functions of compulsory savings accounts in turn.

\subsection{Liquidity insurance}

Compulsory individual accounts protect people by allowing individuals to make withdrawals from the accounts even if the account balance is negative. In this way, the government in effect provides liquidity insurance and alleviates capital-market imperfections. The future compulsory contributions into the savings scheme act as collateral so that the government can provide credit. The relief of liquidity constraints is especially important for the lower middle class workers, who often face borrowing constraints that prevent them from smoothing consumption over time in the face of various shocks. These groups thus benefit from more economic security. By allowing workers to, in fact, access the capital market and thus decouple individual annual consumption levels from individual annual incomes, compulsory savings accounts make lifetime income rather than annual income a more important indicator of welfare.

In the context of a model with involuntary unemployment, Bovenberg and Sørensen (2004) show that compulsory savings accounts can offer more efficient liquidity insurance than tax-financed unemployment benefits. Intuitively, by linking contributions more closely to actual benefits received, compulsory savings accounts contain the adverse incentive effects of providing liquidity insurance. Moreover, in contrast to a simple cut in unemployment benefits, the introduction of mandatory unemployment accounts and the associated liquidity insurance allows the individual to bear the risk of unemployment in a period of life when consumption is higher. Whereas a cut in unemployment benefits would force a cut in consumption when it is already low (assuming that the unemployed are liquidity-constrained and that benefits are lower than wages), achieving the same improvement of the public budget through mandatory contributions to individual unemployment accounts would allow workers to concentrate the cut in consumption in periods when they are employed and which feature lower marginal utility of consumption.

\subsection{Lifetime redistribution}

In the presence of individual accounts, the government can protect the lifetime poor by redistributing resources towards individuals who end up with a low or negative account balance at the end of their working lives. In this way, the government redistributes to the lifetime poor and provides insurance against catastrophic shocks that substantially harm lifetime incomes. Redistribution is thus targeted more closely at the lifetime poor, who are suffering a combination of low-wage incomes and frequent adverse shocks during their lives. The individual savings accounts essentially help to keep track of which individuals fare poorly in life. By thus in effect collecting information on who is lifetime poor, the individual accounts improve the equity-efficiency 
trade-off if the government uses this information to redistribute towards those with low lifetime incomes. The government thus focuses its scarce resources on redistribution from the lifetime rich to the lifetime poor-rather than making politically expedient transfers among various important groups of voters with comparable long-run living standards. Indeed, by cutting out the transfers that merely redistribute resources over the life course and focusing the transfers on interpersonal redistribution to the lifetime poor, the government can reduce distortionary tax wedges on labor supply. The additional information on lifetime incomes essentially allows the government to implement an optimal non-linear lifetime income tax.

In the context of a model with three types of households, Bovenberg and Sørensen (2004) show how individual savings accounts can improve the equity-efficiency trade-off by exploiting information on lifetime incomes to offer a lifetime income guarantee. In particular, the government bails out individuals who end up with a negative account balance. In this way, individual accounts establish an efficiencyenhancing actuarial link between contributions and benefits for high-income and middle-income workers - who currently pay distortionary taxes partly to finance distortionary social benefits to themselves-without reducing net transfers paid to the low-income workers who remain protected by the lifetime income guarantee. In other words, the savings accounts effectively enable the government to implement selective cuts in tax-financed benefits for high-income and middle-income groups without having to reduce these benefits at the bottom of the income ladder. At the same time, by providing liquidity insurance (see Sect. 3.1), the government increases the importance of lifetime income rather than annual income as an indicator of overall welfare.

The individual accounts with a lifetime income guarantee as implemented by Bovenberg and Sørensen (2004) do not improve labor-market incentives for the lifetime poor. Indeed, the individual account system can be viewed as a way to implement low marginal tax rates at the top of the lifetime income distribution. At the bottom of the lifetime income distribution, however, high marginal tax rates remain the inescapable price of redistribution. The government can rely on financial incentives to stimulate the middle class, which accounts for a large share of effective labor input in the economy. However, it must use other instruments to activate the lifetime poor, whose employment is important for maintaining social cohesion in a society. Among other things, the government can focus its active labor market policies and its administrative resources on this group. In particular, the government may collect additional information by closely monitoring job search and health conditions. The government provides benefits on the condition that an able individual gives up leisure time to improve skills or (look for) work. In this connection, workfare may play a useful role; the mere threat of being put on workfare is likely to boost work incentives (see Kreiner and Tranæs 2005).

Individual accounts are particularly attractive if the distribution of life-course incomes is not very skewed compared to the distribution of annual incomes. In that case, annual income is typically not a good indicator for lifetime income; information on lifetime income can thus make lifetime redistribution more efficient. In the modern life cycle with many working women and long periods of full-time or parttime education, a substantial number of workers move between periods of full-time 
work to periods of voluntary (sometimes part-time) absence from the labor market to educate themselves, start up a business, or care for children and/or frail relatives (see e.g. Bovenberg 2005). This makes annual income a poor indicator of lifetime income.

With little lifetime inequality, redistribution of lifetime incomes does not have to be costly. Indeed, in that case, the government does not need to bail out many households with negative account balances. Intuitively, over their life cycles, a large middle class is able to finance its own benefits. This points to the importance of providing individuals with equal opportunities in the beginning of their working lives in the form of good start qualifications provided by basic education. The less polarized a society is in terms of human capital, the less the fiscal system has to redistribute resources from high lifetime-income earners to low lifetime-income earners, and the more the government can limit itself to helping individuals smooth their consumption over the life cycle.

\subsection{Mandatory saving and myopia}

The individual accounts do not escape the trade-off between equity and efficiency to the extent that lifetime incomes are distributed unequally. Liquidity insurance also implies some costs. Lifetime redistribution as well as liquidity and lifetime income insurance give rise to moral hazard; agents have an incentive to minimize their contributions and maximize their withdrawals. The government must therefore regulate withdrawals so that they can be made only for pre-specified purposes. Savings must also be mandatory - at least until a specific upper limit is reached.

In addition to moral hazard, lack of self control and myopia are other reasons for making saving mandatory. Compulsory savings accounts in effect extend mandatory saving aimed at retirement to precautionary saving aimed at social insurance for individuals of working age. By being paternalistic, the government helps individuals who lack self control to implement better consumption smoothing. However, if individuals lack the willpower or cognitive abilities to smooth consumption over their lifetimes, annual disposable income becomes relatively more important than lifetime income as a welfare indicator. Accordingly, the government should base its redistributive policies not only on lifetime incomes (and the associated balances in individual accounts), but also on disposable incomes at each point in time. Intuitively, the government cannot rely on all individuals to allocate their lifetime incomes optimally over their life course, and must therefore be concerned also about the distribution of annual incomes.

A disadvantage of mandatory saving is that the government may force some people to save too much. This can be an important drawback if preferences are heterogeneous and people cannot undo mandatory saving by borrowing. In that case, tax incentives, which respect free choice, can complement limited mandatory saving as an instrument to stimulate individuals to save. Tax incentives, however, typically imply a large deadweight loss, as individuals who would have saved even in the absence of tax incentives take advantage of the tax privileges by simply restructuring their portfolio. To prevent this, the government can target tax subsidies at agents with low financial and human wealth by limiting tax incentives to low levels of saving. 


\subsection{Moral hazard and optimal lifetime insurance}

Another reason why savings schemes may enhance efficiency is moral hazard in insuring human-capital shocks over the life cycle. In particular, agents may be able to affect the probability that the insured contingency occurs. To illustrate, unemployment compensation can harm incentives to find work and remain employable. Another form of moral hazard is benefit cheating, which can occur if the insured conditions are difficult to verify. Individuals may, for example, pretend to be sick or disabled in order to claim sickness or disability benefits. Moral hazard is a problem even for actuarially neutral insurances that charge a premium that is directly related to the expected individual benefit from the insurance. ${ }^{4}$

Various developments increase the dangers of moral hazard and hence make human-capital risks less insurable. As the economy shifts from blue-collar work in industrial sectors to white-collar work in service sectors and knowledge-intensive activities, mental causes of sickness and disability become more prominent. These types of sickness and disability can be less easily verified than physical disabilities. Moreover, an increasing number of workers now moves between periods of full-time work to periods of voluntary absence from the labor market to enjoy leisure, educate themselves, set up a business, or care for children or frail relatives. In such a transitional labor market, it becomes more difficult to separate voluntary periods of inactivity from involuntary unemployment. At the same time, individuals can increasingly affect the probability that they become unemployed by investing in their own employability. In other words, the dividing line blurs between the contingencies that people are responsible for and those for which they are not. These changes in the nature of social risks make it more costly to insure human capital in terms of harming the incentives to accumulate and maintain that capital. At the same time, a more dynamic world economy and a decline of the extended family as an insurance device have increased the demand for such insurance, as people experience more substantial economic insecurity.

Moral hazard gives rise to a fundamental conflict between facilitating insurance and providing incentives to reduce the probability that the insured risk occurs. In particular, reducing the extent of insurance through the introduction of deductibles can combat moral hazard. Deductibles help internalize the social costs of benefit payments, thereby discouraging individuals from making excessive claims on the welfare state. At the same time, however, these deductibles impose costs on risk-averse individuals by reducing insurance through risk pooling. Another way to combat moral hazard is to monitor agents and to regulate their behavior, but this may well be costly in terms of intrusion in private lives.

Individual savings accounts can improve the trade-off between insurance and incentives by facilitating self-insurance over the life course. Specifically, these accounts increase the scope for deductibles without compromising minimum consumption standards of individuals who are hit by temporary adverse shocks. They do so by

\footnotetext{
${ }^{4}$ Whereas the premia of such insurances do not distort the labor market, the benefits harm labor-market incentives if people can affect the probability that they are eligible for these benefits by changing their labor-market behavior.
} 
allowing individuals who suffer from liquidity constraints when they are hit by an adverse shock to shift the payment of deductibles to the periods in which they can more easily afford these costs. Individuals can thus self-insure over their life course, and do not have to rely on insurances that gives rise to moral hazard. Risks can be self-insured on a lifetime basis, and thus do not have be insured on a day-to-day basis. Indeed, risks that may seem large on an annual basis may in fact be quite small when considered over an entire lifetime. To illustrate, two unemployment spells of half a year reduce lifetime incomes of an individual with a full-time working career of 30 years by only about $3 \%$.

The accounts, in fact, combine a number of risks that occur during different periods of an individual's life in a single insurance contract with a deductible that is conditioned on the aggregate loss during the life course. Drawing on Arrow (1971), Gollier and Schlesinger (1995) show that an umbrella insurance contract with a deductible on the aggregate loss dominates separate insurance contracts with separate deductibles for each type of loss if these individual losses are imperfectly correlated. Intuitively, insurance protection is most valuable for the states in which several losses occur simultaneously. An umbrella insurance policy that adjusts the deductible on each separate loss to the outcome of the other risks in the form of a straight deductible based on the aggregate loss provides the best protection against large aggregate losses for a given insurance budget. Hence, an individual account that insures aggregate lifetime risk with a single deductible conditioned on aggregate lifetime losses dominates separate insurance contracts with their own deductibles for risks faced in different periods of an individual's lifetime. For a given level of insurance cover, separate policies for risk experienced in each period underindemnify risk-averse individuals for high levels of aggregate losses during the life course and overindemnify them for losses that are experienced only in a single period. Compared to separate insurance policies, the umbrella insurance contract provides better protection in the worst-case scenario of a succession of adverse shocks during the life course in exchange for less protection in other cases.

The potential of individual accounts in improving the trade-off between insurance and incentives depends crucially on the extent to which individuals face correlated shocks during their lifetimes. The potential welfare gains of individual savings accounts are large if various income shocks are uncorrelated across time and among each other. In that case, annual incomes are poor indicators of lifetime incomes, and income shocks are, in fact, only small in the context of an entire lifetime. There is thus ample scope for self-insurance by pooling risks facing a single individual. If shocks are strongly and positively correlated, in contrast, risks do not become much smaller in a lifetime context (compared to an annual context). In particular, some individuals are always unlucky and therefore remain poor, while others seem to continuously "strike it rich." Risks then remain catastrophic, even when viewed over the entire life course. Self-insurance is then costly, and pooling risks across individuals (rather than just intertemporally for each single individual) through insurance creates substantial value. Also, the scarring effect of unemployment on human capital makes insurance more valuable. More generally, labor-market risks tend to be correlated in the presence of dual labor markets in which insiders enjoy high incomes throughout their lives, while outsiders must make do with insecure jobs and tend to suffer from 
frequent and long-lasting unemployment. Hence, long unemployment durations in slow-moving labor markets make individual accounts less attractive as an instrument to provide lifetime income insurance.

For each type of human-capital risk, another combination between insurance and self-insurance through saving is optimal, depending on the magnitude of the risk in terms of the potential drop in lifetime income and the potential danger of moral hazard because of endogeneity and non-verifiability of the insured risk. Selfinsurance should be relatively important for non-catastrophic risks that people can affect through non-verifiable actions, such as short-term unemployment and the first sickness days. Stiglitz and Yun (2002) explore the optimal mix of self-insurance through savings accounts and tax-financed insurance. They show that self-insurance should play a more prominent role if risk aversion is low, moral hazard is important, various risks are uncorrelated across time and among each other, and these risks are only small in a lifetime perspective. They also demonstrate that the optimal extent of self-insurance depends on the history of an individual. Self-insurance should optimally be the most important for those individuals who have not experienced adverse shocks early in life so that they are not likely to end up being lifetime poor. Also here, the conclusion is thus that saving schemes can play a more important role in enhancing incentives for the middle- and higher incomes than for the lifetime poor. The optimal mix between saving and insurance may also vary between workers in different sectors in the economy. This provides an argument for a role for employers and employees on a sectoral level in determining the optimal mixes between saving and insurance. Indeed, individual savings schemes may be incorporated in collective sectoral agreements. These agreements may provide for mandatory contributions into both specific employee insurances with deductibles and individual savings schemes from which individuals can draw to pay deductibles.

Bovenberg and Sørensen (2006) investigate the optimal structure of lifetime income taxation and social insurance aimed at both lifetime income redistribution and disability insurance, which can be interpreted as insurance against all kinds of idiosyncratic shocks to human capital. They show that-even in the absence of moral hazard-full insurance against these idiosyncratic shocks is not optimal. The reason is that imperfect insurance encourages workers to self-insure by raising their labor supply, thereby alleviating the distortionary impact of redistributive labor taxation. Hence, a tension exists between lifetime redistribution and insurance against human-capital shocks. By harming labor supply, social insurance imposes a negative externality on the redistributive branch of the government. The greater the weight attached to redistribution towards the lifetime poor with low skills, the less the government can allow the higher skilled to insure themselves fully against disability risk. This result suggests that the government cannot leave individuals completely free to use their social security contributions to buy actuarially fair insurances. Against this risk of overinsurance, however, stands the risk of underinsurance due to selection giving rise to excessive transaction costs. In any case, a hybrid system of insurance and self-insurance would typically be optimal, depending on moral hazard, selection, risk aversion and redistributive preferences and the associated distortionary taxes. 


\subsection{Welfare accounts for public services}

In outlining the case for individual savings accounts, we have focused on insuring shocks affecting the earning capabilities of individuals. Similar arguments for and against savings schemes apply to the financing of health care. In particular, savings schemes can be part of a three-pillar model in health-care financing involving a hybrid system of saving, insurance and redistribution. This model involves, first, government assistance for those who cannot afford a minimum level of medical care (i.e. redistribution); second, medical insurance for catastrophic events supplemented by limited insurance for other events (i.e. insurance based on risk pooling); third, compulsory individual medical saving for financing deductibles and coinsurances (i.e. consumption smoothing and self-insurance). The optimal mix between these three pillars depends on the particular type of health-care cost considered. As explained above for social insurance, saving schemes are most attractive for costs that are distributed rather uniformly across individuals (seen over the life cycle as a whole).

The principle of individual savings accounts can be applied to finance user fees for not only medical care but also other services, such as higher education and child care. If individuals pay these costs from their individual savings accounts and can thus smooth these costs over their entire lifetime, the government can rely more on consumer sovereignty for selecting the level, quality and nature of the service, and thus does not have to impose strict regulations (e.g. by rationing individuals).

\section{The design of individual accounts: alternative proposals}

In the literature, several types of individual savings accounts have been proposed. Fölster (1999) takes the currently paid taxes as the point of departure, reducing taxes by an amount corresponding to the mandatory contributions to the individual accounts (IAs) and premiums for lifetime income insurance. He proposes a narrow and a broad implementation of the personal savings account. The narrow version incorporates benefits for unemployment, sickness, child care, parental leave and housing into the accounts. The minimum guaranteed pension is calibrated so as to ensure that aggregate pensions paid out under the account system (including the positive IA balances) equal the total amount of pensions paid out under the present system. This means that individuals featuring a relatively high wage towards the end of their career (and who would therefore be entitled to a relatively high pension under the current system) but who nevertheless end up with a negative IA balance will tend to lose from the reform, since they are entitled to only a relatively low minimum pension.

In the broad version of the proposed accounts, Fölster (1999) also includes pensions, health-care spending, and university tuition in the accounts. Lifetime income insurance is provided by computing a minimum guaranteed pension based on the current rules for computing contributory pensions. The guaranteed pension thus rises with the contributions into the accounts. If this pension exceeds the annuity that can be financed from the resources in the savings account at age 65, the lifetime income insurance pays up the difference. In addition, if the account balance becomes negative during the working life and reaches a certain debt limit, this income insurance pays 
additional withdrawals and the individual does not have to further run up the debt in his account. The insurance payments are financed through an explicit insurance premium on labor income. As a consequence, marginal tax rates on labor income remain positive for individuals who do not expect to benefit from the income guarantee. In applying the system to Sweden, Fölster (1999) computes an insurance premium that amounts to about $20 \%$ of all payments flowing into the accounts. In addition, the system includes redistribution from men to women because the conversion factor for computing the annuity is the same for both sexes (even though women tend to live longer than men do). Also, parents benefit from a higher conversion factor at retirement, a policy that helps people with children.

Orszag and Snower (2002) focus on unemployment accounts. Workers would be required to put mandatory contributions in their unemployment account to finance withdrawals when unemployed. Individuals with a zero balance would remain entitled to regular unemployment assistance. In addition, the contributions of workers earning low incomes could be subsidized. These subsidies and the unemployment assistance benefits paid to the unemployed with zero balances would be financed by taxes on the contributions of other workers. In this way, marginal taxes on labor income remain positive for all workers. Orszag and Snower (1997) extend this proposal to human capital accounts covering education and training and health accounts applying to sickness, disability and health insurance. The government could redistribute resources across people's accounts in a balanced budget manner: contributions of lowincome groups could be subsidized, while contributions of high-income groups could be taxed. The taxes could be used also to finance the withdrawals of those whose account balances fall below a certain minimum. Moreover, to fight cream skimming and selection, the pricing of insurance would have to be regulated.

Stiglitz and Yun (2002) explore social-insurance accounts that are integrated with the retirement system. Whereas the accounts raise expected utility ex ante, they do not guarantee that all agents are better off ex post. In particular, agents who have suffered frequent and lengthy spells of unemployment during their lives may end up with lower retirement benefits than with unemployment benefits that are entirely financed through taxes. Within this setting, Stiglitz and Yun (2002) explore which share of unemployment benefits should be optimally financed from savings accounts from the point of view of maximizing ex-ante utility of the workers. They argue that explicit transfers from high-skilled to low-skilled workers could mimic the transfers between these groups implicit in the current unemployment insurances without undoing the efficiency gains from individual accounts in combating moral hazard.

Stiglitz and Yun (2002) argue also in favor of an integrated lifetime insurance program under which people can borrow against their compulsory pension savings to provide cover for not only unemployment but also other risks, including adverse health and disability shocks. They argue that all social insurances should be integrated unless risks are perfectly correlated with each other. The smaller the correlation between the various shocks, the larger become the benefits from integrating the various insurances. In such an integrated program, the optimal amount of self insurance would depend on shocks experienced earlier in life. An individual who has not experienced many adverse shocks early in life can self-insure more risks later in life. However, in order to provide lifetime income insurance, the government has to bail 
out individuals who have already experienced various serious adverse shocks when they enter retirement. These individuals cannot self-insure, however, as the cumulation of the various adverse shocks would force their living standards below a socially acceptable level.

Leijnse et al. (2004) propose a three-pillar system. The first pillar is tax-financed and includes transfer programs that tend to involve significant lifetime redistribution and only limited moral hazard. The third pillar includes voluntary saving schemes. The second pillar, which may include income-related benefits for individuals experiencing unemployment or sickness or taking parental leave, involves mandatory contributions to individual accounts that offer neither a lifetime income guarantee nor liquidity insurance. As a direct consequence, some individuals who make frequent withdrawals and exhaust their accounts would lose ex post. The second pillar, however, would be a mixture between insurance and saving. Hence, on a sectoral level, social partners can force workers to use part of their contributions to buy insurance. In that case, potential ex post losses for those who make frequent withdrawals would be contained, as would be the potential welfare gains from reduced moral hazard. Indeed, the optimal mix between saving and insurance would depend on the scope for moral hazard. In particular, the share of saving and self-insurance would increase if individuals bear a greater personal responsibility for an event.

Bovenberg et al. (2006) evaluate a proposal of the Danish Economic Council (2005, Chap. VI). Each citizen in the age group from 18 years until the official retirement age of 65 years would be required to deposit a certain percentage of his labor income in an individual account every year. Whenever a person receives certain socialinsurance benefits according to the current eligibility rules (which are assumed to be unchanged), his individual account would be debited by the corresponding amount, and the balance on the IA would be carried forward with the after-tax interest rate on short-term government bonds. If the IA balance is positive at the time of retirement, the balance is converted into an annuity that is added to the ordinary public retirement pension. If the IA balance is negative when the individual reaches the retirement age, the account is simply set to zero. The following programs, which involve a relatively low degree of interpersonal redistribution, are included in the accounts: early retirement benefits, grants to students in higher education, short-term unemployment benefits, short-term sickness benefits, child benefits, and parental leave benefits.

The system features a lifetime-income guarantee ensuring that no person can be worse off in any realized contingency than under the existing tax-transfer system, while individuals with positive account balances are better off. This outcome follows from two features of the proposal. First, for each individual taxpayer the mandatory contribution to the IA is matched by a corresponding tax cut. Second, every taxpayer can take up benefits under the current eligibility rules regardless of the (negative or positive) balance on his IA, and no taxpayer can end up with a lower retirement pension than under the present system. However, the positive IA balances that are added to the public pension obviously harm the government budget. Bovenberg et al. (2006) show that this so-called static revenue loss-i.e. the change in net public revenue that would occur if behavior were unchanged-increases with the amount of interpersonal lifetime redistribution implied by the programs that are included in the account system. In fact, one can interpret the static revenue loss as the distributional loss from 
the introduction of individual accounts. As an offset to the static revenue loss, there are dynamic revenue gains reflecting the budgetary impact of behavioral changes. These revenue gains can be viewed as the efficiency gains from the reform, arising partly from the positive incentive effect of a closer actuarial link between contributions and benefits, and partly from reduced moral hazard as individuals effectively finance more of their own social benefits.

Using rather conservative assumptions for labor-supply elasticities and data for the actual Danish income distribution, Bovenberg et al. (2006) find that the dynamic revenue gains dominate the static revenue losses for small individual accounts. The dynamic revenue gains are driven mainly by the impact of a lower effective benefit rate on the incentives to take up public benefits. The overall revenue gain implies that the introduction of individual accounts is Pareto improving. Neither the government nor individuals are worse off after the reform. Whereas individuals are more uncertain about the level of their retirement benefit, they cannot be worse off in any contingency. Their ex-ante welfare level, which accounts for the additional risk from the introduction of the IAs, thus cannot fall. The key explanation for the Pareto improvement is that the programs included in the accounts have a much smaller impact on the distribution of lifetime income than on the annual income distribution. This reduces the static revenue losses from individual accounts protecting the lifetime poor compared to policies that protect individuals from suffering income losses in each year. Individual accounts, which provide information on who is lifetime poor, thus help to substantially reduce the efficiency losses from redistributing lifetime incomes.

Future research will have to show whether similar results can be derived for other countries and other programs. The conditions for introducing individual accounts in the universal welfare states of the Scandinavian countries seem to be particularly attractive. First of all, the distribution of lifetime incomes is relatively equal, while a broad coverage of social transfer programs implies that taxpayers end up receiving substantial public transfers over their life course. Second, marginal tax and benefit rates are high so that the efficiency and budgetary gains from improved incentives are substantial. Whereas the first factor contains the static revenue losses, the second factor boosts the dynamic revenue gains.

The proposed savings schemes described above are all mandatory, with the potential disadvantage that they may force some people to save too much. As an alternative or supplement to mandatory schemes, the government may wish to promote voluntary saving schemes - say, through tax incentives. An example of a voluntary saving scheme is the so-called life-course scheme introduced in the Netherlands. The funds in this scheme can currently be used only for financing leave. In the future, however, the government may allow the owners of these accounts to utilize the funds for financing deductibles in social insurance. These voluntary schemes seem particularly suited for high- and middle-income earners who are not likely to benefit from the income guarantees provided by social assistance. For others, means-tested social assistance erodes precautionary saving motives. For these groups, the government thus cannot rely on voluntary saving schemes, unless the government provides substantial tax incentives and appropriate defaults encouraging people to save. 


\section{Concluding remarks}

Our analysis suggests that individual accounts can play a useful role in financing social benefits that have only little redistributive power in a life-cycle perspective and give rise to serious moral hazard. For such benefits, savings accounts can enhance labor-market incentives at a relatively low cost in terms of a more unequal distribution of lifetime incomes. This is especially so if savings accounts are accompanied by labor-market institutions that combat long-term employment and facilitate rapid turnover and by social policies that provide a lifetime income guarantee and ensure an equal distribution of human capital. As the changing nature of social risks makes social insurance more expensive in terms of distorted labor-market incentives, individual accounts with a lifetime income guarantee seem to be an attractive alternative to simple cuts in taxes and benefits. Indeed, such accounts can continue to provide substantial income security at a time when a dynamic world economy confronts many people with substantial risks. In this way, individual accounts can help protect the social legitimacy of a competitive market system that stimulates innovation and growth but also gives rise to substantial risks associated with creative destruction.

For each type of human capital risk, another combination between insurance and self-insurance through saving is optimal, depending on the magnitude of the risk in terms of the potential drop in lifetime income and the potential danger of moral hazard because of endogeneity and non-verifiability of the insured risk. Selfinsurance should be relatively important for non-catastrophic risks that people can affect through non-verifiable actions, such as short-term unemployment and the first sickness days.

Apart from the changing nature of social risks and the continued demand for income security, several factors have made individual accounts in social insurance more attractive. First of all, modern information and communication technologies enable governments to keep systematic records of the contribution and withdrawal histories of their citizens. Second, more efficient capital markets allow individuals to smooth their consumption over their life courses. By thus allowing individuals to decouple annual consumption from annual disposable incomes, better functioning capital markets make lifetime rather than annual incomes better indicators of overall welfare. Moreover, financial innovation allows private financial institutions to administer the compulsory savings accounts. A further reason for the increased attractiveness of individual accounts is that they are fully portable between jobs. Hence, social insurance does not tie workers to their initial employer. This facilitates labor mobility and the flexibility of the labor market. It is also consistent with the emancipation of the worker, who becomes more independent of specific employers.

Individual accounts may have political-economy implications. In particular, by separating lifetime redistribution from consumption-smoothing and insurance, individual accounts increase the transparency of lifetime redistribution. This may weaken the political support for this redistribution. Another factor that may work in the same direction is that the middle class no longer benefits from redistribution, which is now more closely targeted at the lifetime poor (see, e.g., Cassamatta et al. 2000). At the same time, however, individual accounts give individuals a stronger sense of ownership and personal responsibility. This may strengthen popular support for the welfare 
state and the liquidity and lifetime insurance it provides. Stronger personal ownership may also make it more difficult for the government to change benefit rules, thereby reducing political risks.

The lifetime income guarantee implies also that, while marginal rates are cut for others, marginal tax rates tend to remain high for the lifetime poor. The employment gap between low-skilled and high-skilled workers may thus increase unless the government focuses active labor-market policies on the bottom of the labor market and employs instruments other than financial incentives to activate the lifetime poor. A related drawback may be that, although the lifetime poor may not become worse off in absolute terms, they may become poorer compared to the lifetime rich. This is a serious drawback if people care more about relative incomes than absolute incomes. Indeed, in the presence of such standard-of-living utilities, optimal marginal tax rates at the top of the income distribution would be positive.

Mandatory individual savings accounts can be a useful component of an overall social policy package. In addition to equal opportunities at the start of life through an equal distribution of human capital, such a policy package should provide some form of lifetime income guarantee. By using information on lifetime incomes, redistribution implicit in such an income guarantee can occur at lower efficiency costs. Moreover, actuarially fair links between contributions and expected benefits alleviate the labor-market distortions associated with social insurance for middle- and high incomes. Finally, by facilitating consumption smoothing through savings schemes offering liquidity insurance, the government increases the scope for self-insurance, thereby combating moral hazard in social insurance. Through all these channels, savings accounts support social policy by reducing the costs that are associated with an effective mix of redistribution, social insurance and consumption smoothing.

Acknowledgement We wish to thank Ruud de Mooij, an anonymous referee, Paul de Beer, Berthold Leeftink and the participants of the Netspar-SER-CPB conference on "Reinventing the Welfare State" on April 27 and 28, 2006, in the Hague for valuable comments on an earlier draft of this paper. All remaining errors and shortcomings are our own responsibility.

\section{References}

Arrow, K. J. (1971). Essays in the theory of risk bearing. Chicago: Markham.

Bovenberg, A. L. (2005). Balancing work and family life during the life course. De Economist, 153.

Bovenberg, A. L., \& Sørensen, P. B. (2004). Improving the equity-efficiency trade-off: mandatory savings accounts for social insurance. International Tax and Public Finance, 11, 507-529.

Bovenberg, A. L., \& Sørensen, P. B. (2006). Optimal taxation and social insurance in a lifetime perspective (EPRU working paper 06-01). Economic Policy Research Unit, University of Copenhagen.

Bovenberg, A. L., Hansen, M. I., \& Sørensen, P. B. (2006). Individual accounts and the life-cycle approach to social insurance. Mimeo.

Cassamatta, G., Cremer, H., \& Pestieau, P. (2000). Political sustainability and the design of social insurance. Journal of Public Economics, 75, 341-364.

Coronado, J. L., Fullerton, D., \& Glass, T. (2000). The progressivity of social security (NBER working paper 7520). Cambridge, MA.

Danish Economic Council (2005). Dansk Økonomi, Forår 2005 (The Danish Economy, Spring 2005). Copenhagen.

Danish Ministry of Finance (2002). Fordeling og Incitamenter 2002 (Distribution and incentives 2002). Copenhagen. 
Falkingham, J., \& Harding, A. (1996). Contributions to economic analysis: Vol. 232. Poverty alleviation versus social insurance systems: a comparison of lifetime redistribution. Amsterdam: North Holland.

Fölster, S. (1999). Social insurance based on personal savings. The Economic Record, 75, 5-18.

Gollier, C., \& Schlesinger, H. (1995). Second-best insurance contract design in an incomplete market. Scandinavian Journal of Economics, 97, 123-135.

Gustman, A. L., \& Steinmeier, T. L. (2000). How effective is redistribution under the social security benefit formula? (NBER working paper 7597). Cambridge, MA.

Hansen, M. I. (2005). Medborgerkonti-velfærdsydelser finansieret af individuelle opsparingskonti (Citizen accounts - social insurance financed by individual savings accounts). Master thesis, Department of Economics, University of Copenhagen.

Hussénius, J., \& Selén, J. (1994). Skatter och socialforsäkringer över livscykeln-en simuleringsmodell (Taxes and social insurance across the life cycle — a simulation model). Ds 1994: 86 (ESO), Swedish Ministry of Finance, Stockholm.

Kreiner, C. T., \& Tranæs, T. (2005). Optimal workfare with voluntary and involuntary unemployment. Scandinavian Journal of Economics, 107, 459-474.

Leijnse, F., Goudswaard, K., Plantinga, J., \& van der Toren, J. P. (2004). A different attitude to social security. In Life course policy conference, SER, the Hague, June 3-4, 2004.

Liebman, J. B. (2001). Redistribution in the current U.S. social security system (NBER working paper 8625). Cambridge, MA.

Nelissen, J. H. M. (1998). Annual versus lifetime income redistribution by social security. Journal of Public Economics, 68, 223-249.

O’Donoghue, C. (2001). Redistribution in the Irish tax-benefit system. Ph.D. thesis, London School of Economics, London.

Orszag, J., \& Snower, D. (1997). Expanding the welfare system: a proposal for reform. European Economy, 4, 101-118.

Orszag, J., \& Snower, D. (2002). From unemployment benefits to unemployment accounts (IZA discussion paper No. 532). Institute for the Study of Labor, Bonn.

Pettersson, T., \& Pettersson, T. (2003). Fördelningen ur et livscykelperspektiv (Distribution from a life cycle perspective). Bilaga 9 till långtidsutredningen, Swedish Ministry of Finance, Stockholm.

Stiglitz, J., \& Yun, J. (2002). Integration of unemployment insurance with retirement insurance (NBER working paper 9199).

Ter Rele, H. (2005). Measuring lifetime redistribution in Dutch collective arrangements (CPB Document No. 79). CPB Netherlands Bureau for Economic Policy Analysis, the Hague. 